\title{
Two-year old girl with glial choristoma presented in a thyroglossal duct cyst
}

\author{
Oğuzhan Şal ${ }^{1 \oplus}$, Mehmet Ali Özen ${ }^{2 \oplus}$, Önder Peker ${ }^{3 \oplus}$, Egemen Eroğlu ${ }^{4 \oplus}$ \\ ${ }^{2}$ Department of Pediatric Surgery, ${ }^{1}$ Koç University School of Medicine, İstanbul; Departments of ${ }^{3}$ Pathology and ${ }^{4}$ Pediatric Surgery, \\ American Hospital, Vehbi Koç Foundation, İstanbul, Turkey.
}

\begin{abstract}
Background. Neuroglial choristomas are rare entities that are composed of differentiated neuroectodermal cells presenting where they do not belong.

Case. Here in this paper, we represent a two-year old patient with a very rare presentation of neuroglial choristoma which manifested itself within a thyroglossal duct cyst. In this paper we will also discuss pathogenesis, clinical manifestation, differential diagnosis and management of the neuroglial choristomas.
\end{abstract}

Conclusion. In conclusion we believe this unique case may aid in understanding the pathophysiology, differential diagnosis, and management of this rare congenital anomaly.

Key words: thyroglossal duct, neuroglial, choristoma, sistrunk.

Neuroglial choristomas are rarely seen in pediatric patients; they are usually located within the head and neck region. Unlike other cystic neuroectodermal pathologies such as meningoencephaloceles, they are not connected to the subarachnoid space and they do not have direct connection to central nervous system. ${ }^{1}$ Furthermore they are not associated with any other neoplasia.

In this paper we present a case in which a twoyear-old girl presents with a hard, firm swelling in the anterior midline neck region which has progressively enlarged.

\section{Case Report}

A two-year old girl presented with a mass located at the anterior midline neck. Caregivers stated that they noticed the mass since birth; however, it had progressively enlarged during the last 3 months. Physical examination revealed a round, firm, painless mass, $4 \times 4 \mathrm{~cm}$ diameter in size (Fig. 1). Differential diagnosis was made in terms of other congenital anomalies or malignancies. Tumor biomarkers were within normal ranges. Complicated thyroglossal cyst was reported on preoperative ultrasonography and magnetic resonance imaging (MRI) (Fig. 2). The patient underwent Sistrunk operation which included resection of the specimen and hyoid bone section over it (Fig. 3). Post-operative outcomes were unremarkable. Histopathologic examination with Hematoxylin-Eosin (H\&E) and Glial Fibrillary Acidic Protein (GFAP) revealed a heterotopic brain tissue which was proportional with the size of the intermingled thyroglossal cyst tissue without basal membrane invasion and angiogenesis (Figs 4, and 5). Neuroglial tissue was ruled as compatible with choristoma. The patient did not require further treatment. Informed consent from the patient's legal guardians were given to publish the findings of the case.

$凶$ Oğuzhan Şal

osal13@ku.edu.tr

Received 12th July 2019, revised 10th November 2019,

12th March 2020, accepted 13th March 2020. 


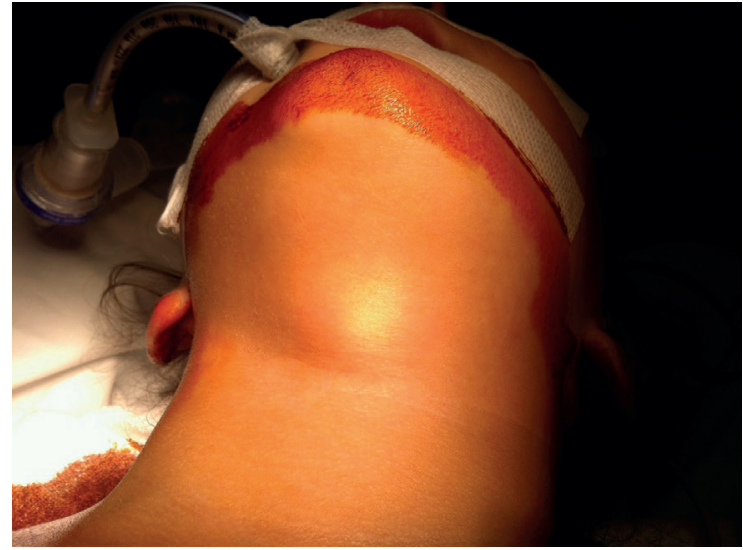

Fig. 1. Patient's preoperative image.

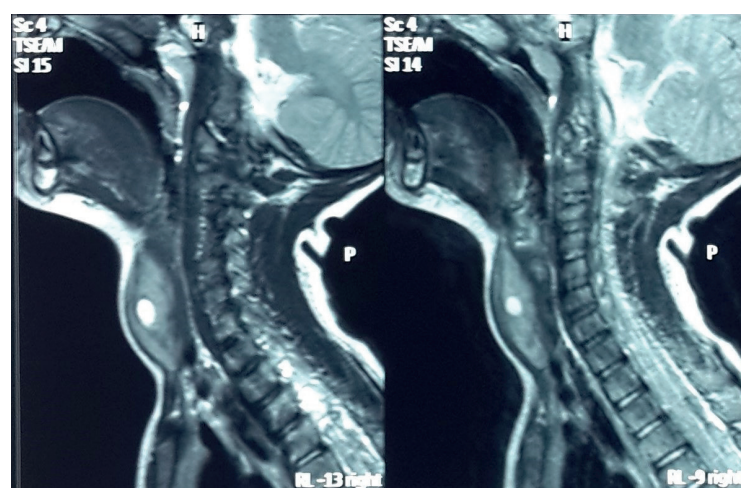

Fig. 2. Magnetic resonance imaging section of the neck.

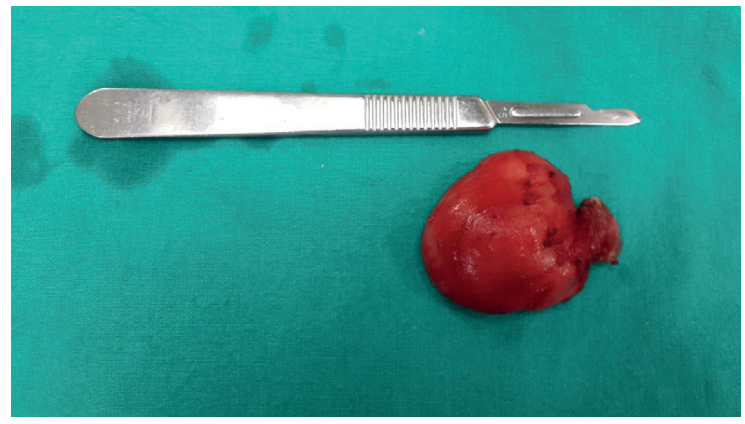

Fig. 3. Macroscopic appearance of the mass.

\section{Discussion}

Neuroglial choriostomas (NC) are heterotopic brain tissue, which can involve various locations, including the brain, nose, nasopharynx, and oropharynx. $^{2}$

Pathogenesis of neuroglial chorsitomas are not clear, there are various theories trying to acknowledge the pathogenesis. One of the various theories suggests that neuroglial heterotopias are vestigial or absorbed components of encephaloceles which had formed before. ${ }^{2}$ Another one proposes that these lesions are caused by displacement of neural crest cells within the region before termination of neural cell migration and further differentiation into heterotopic tissues which would represent themselves later on. ${ }^{3}$ Furthermore development, separation and the tract that had been followed by the cranial nerves can be the etiology behind the neuroglial choristomas within head and neck region. ${ }^{4}$ For our case one of the theories mentioned in the literature can enlighten us about the pathogenesis of this case. During invagination of the previously thickened endodermal thyroglossal duct, the nerve tissue innervating the mucosa of the posterior onethird of the tongue is entrapped within this invagination and formed the glial tissue within the duct cyst. ${ }^{5}$ Although many theories have been constructed concerning the pathogenesis of neuroglial choristoma; according to our opinion the last one could be the most related theory which acknowledges the anatomical region and pathogenesis of our case. However, it is still a mystery to us why neuroglial choristoma was formed within a thyroglossal duct cyst.

The lesion in this case did not manifest any neoplastic behavior such as stromal and basal membrane invasion, metastasis and angiogenesis through the mass. These histopathologic features of the mass rules out any midline cervical neoplasms. Furthermore, the anatomic site and the size of the lesions accounted for the possible symptoms. Cervical midline choristomas may cause swelling, feeding difficulties, dyspnea, dysphagia, and mechanical obstruction of the airway.

In this case, differential diagnoses of an anterior neck mass include developmental lesions such as thyroglossal duct cyst, ranula, branchial cleft cyst, hygroma, teratoma, neuroglial choristoma, neoplastic lesions such as thyroid, parathyroid and lymphoproliferative neoplasms, reactive lymphadenitis secondary to infections and autoimmune diseases. ${ }^{6,7}$ Differentiation between 


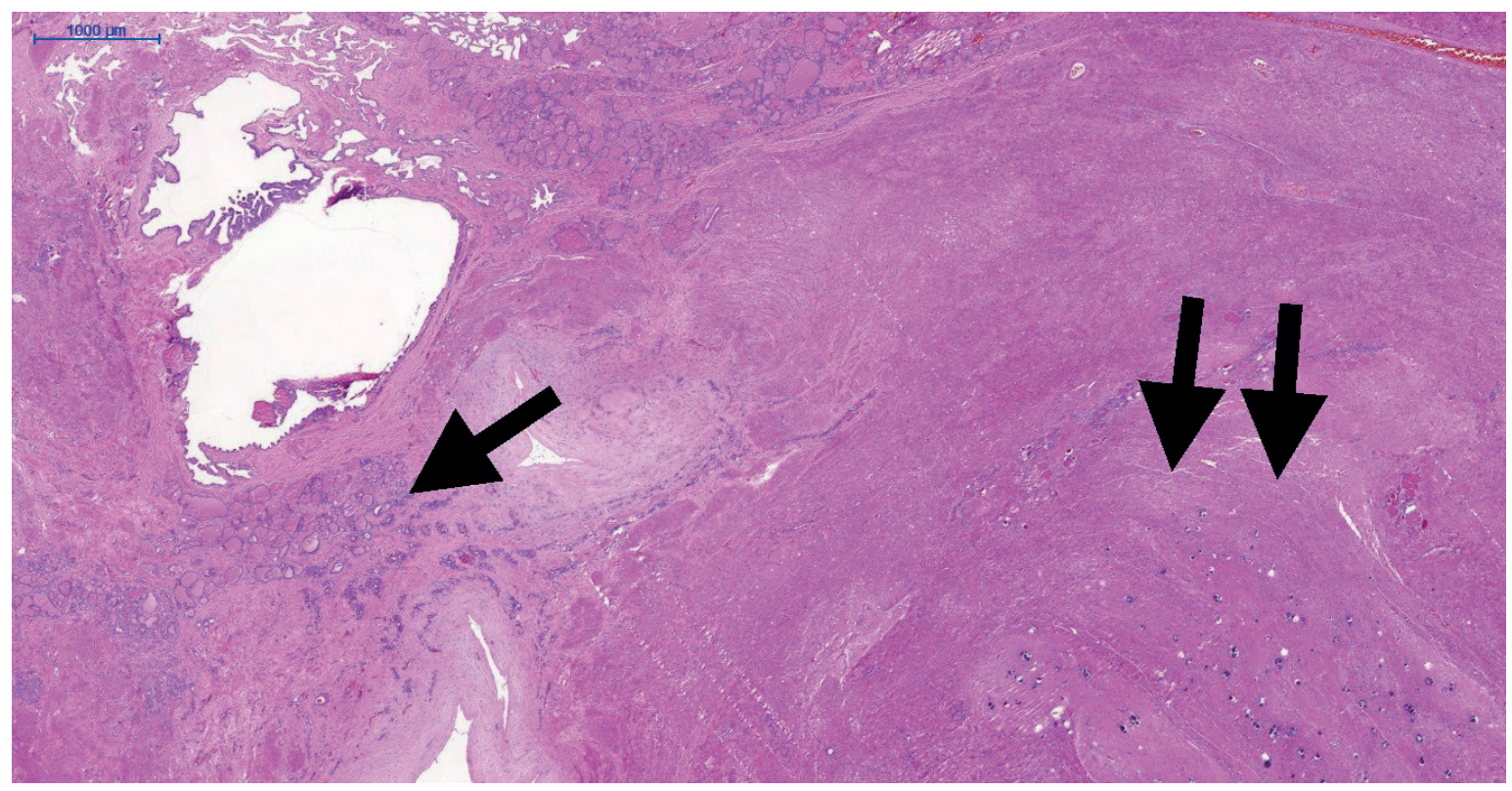

Fig. 4. Histopathologic examination of the mass confirmed the neuroglial choriostoma. Cyctic thyroid tissue (single arrow) and mature glial tissue with psammomas (double arrow). (HEx40).

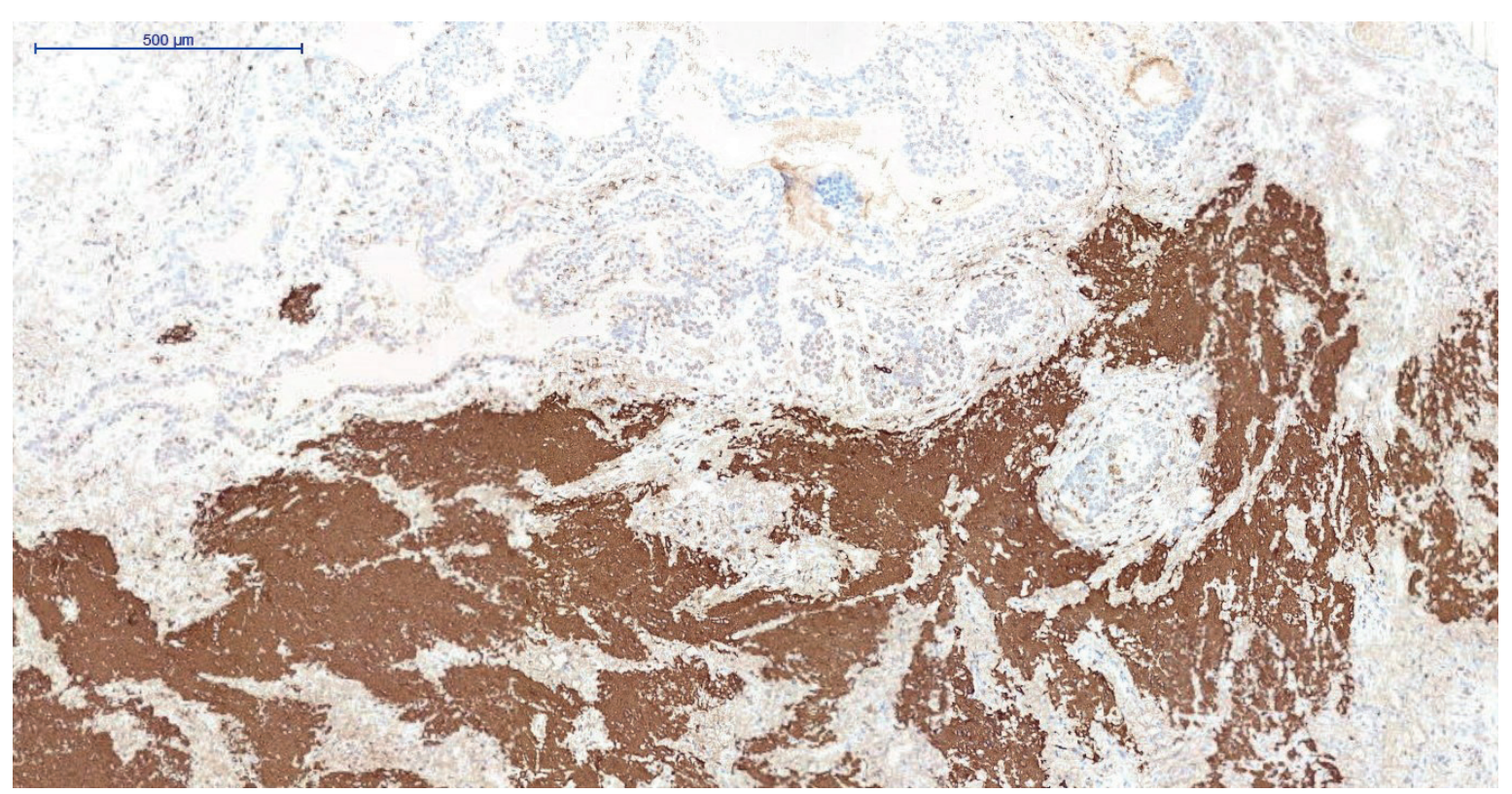

Fig. 5. Neuroglial tissue with Glial Fibrillary Acidic Protein (GFAPx40).

these entities can be done via radiological imaging such as ultrasonography and MRI. ${ }^{8}$ However, MRI is superior to USG by its ability to demonstrate anatomy of the mass in more detail. ${ }^{9}$ Ideally a combination of both MRI and USG imaging studies will provide much better comprehension of anatomy and pathology.
In addition to neuroglial choristomas, teratomas also have a solid part beside a cystic part. ${ }^{10}$ Furthermore, these solid parts are visible in MRI. ${ }^{11}$ When they are set side by side with brachial cleft cysts; neuroglial choristomas do not have cyst walls as thick as cystic hygromas; and they are not confined to nasopharynx 
and oropharynx like cystic hygromas. ${ }^{12}$ Furthermore, a cystic hygroma has an enhancing T2 signal due to its composition. In contrast to ranula; neuroglial choristoma do not have any discoloration that can be seen from outside; also the etiology of ranula is different from a neuroglial choristoma. ${ }^{13}$ Ranulas are caused by blocked drainage of saliva and epithelial debris. ${ }^{13}$ However, the definitive diagnosis of an anterior cervical mass can be declared by histopathologic examination of the specimen.

The mainstay treatment of neuroglial choristoma is surgery; however, there are some key points that will allow the surgeon and the patient to obtain better outcomes. One of them is the identification of the anatomical landmarks in detail to see the upmost anatomical functionality and aesthetic outcomes. The second point is to distinguish between neuroglial choristoma and other neuroectoderm derived pathologies such as meningoencephalocele; this is a quite vital point because connection between subarachnoid space would change the operation and would definitely have an impact on the post-operative period. The third point is to observe enough to allow vital neurovascular structure to mature so that it is not harmed during surgery due to its close proximity to lesion; also the blood volume of the patient would be greater in case of any hemodynamic instability during the operation.

In conclusion both neuroglial choristomas and thyroglossal cysts are congenital disorders of the midline. However, to the best of our knowledge their association has not previously been documented. Although in this paper we tried to construct possible pathophysiological pathway regarding how a neuroglial choristoma forms; there are spots in pathophysiology and anatomy of this case that needs to be further clarified; this unique case may aid in understanding the pathophysiology, differential diagnosis, and management of this rare congenital anomaly.

\section{REFERENCES}

1. Husein OF, Collins M, Kang DR. Neuroglial heterotopia causing neonatal airway obstruction: presentation, management, and literature review. Eur J Pediatr 2008; 167: 1351-1355.

2. Klein MV, Schwaighofer BW, Sobel DF, Fantozzi RD, Hesselink JR. Heterotopic brain in the middle ear: CT findings. J Comput Assist Tomogr 1989; 13: 10581060.

3. Bychkov V, Gatti WM, Fresco R. Tumor of the tongue containing heterotopic brain tissue. Oral Surg Oral Med Oral Pathol Oral Radiol 1988; 66: 71-73.

4. Abdelsayed RA, Wetherington RW, Bent JP 3rd, Sharpe DE. Glial choristoma of the tongue: a case report and review of the literature. Oral Surg Oral Med Oral Pathol Oral Radiol Endod 1999; 87: 215222.

5. Hegazy A. Clinical embryology for medical students and postgraduate doctors. Riga: Lap Lambert Academic Publishing, 2014.

6. Brown RL, Azizkhan RG. Pediatric head and neck lesions. Pediatr Clin North Am 1998; 45: 889-905.

7. Meier JD, Grimmer JF. Evaluation and management of neck masses in children. Am Fam Physician 2014; 89: 353-358.

8. Meuwly JY, Lepori D, Theumann N, et al. Multimodality imaging evaluation of the pediatric neck: techniques and spectrum of findings. Radiographics 2005; 25: 931-948.

9. Turkington J, Paterson A, Sweeney L, Thornbury GD. Neck masses in children. Br J Radiol 2005; 78: 75-85.

10. Barksdale EM Jr, Obokhare I. Teratomas in infants and children. Curr Opin Pediatr 2009; 21: 344-349.

11. Malik A, Odita J, Rodriguez J, Hardjasudarma M. Pediatric neck masses: a pictorial review for practicing radiologists. Curr Probl Diagn Radiol 2002; 31: 146-157.

12. Sheth S, Nussbaum AR, Hutchins GM, Sanders RC. Cystic hygromas in children: sonographicpathologic correlation. Radiology 1987; 162: 821-824.

13. Harrison JD. Modern management and pathophysiology of ranula: literature review. Head Neck 2010; 32: 1310-1320. 